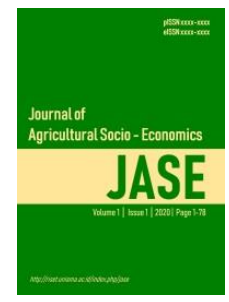

\title{
Analisis Rantai Pasok Komoditas Cengkih Hutan di Maluku
}

\author{
Esther Kembauw $^{1}$, Asri Subkhan Mahulette ${ }^{1 *}$, Anna Yuliana Wattimena ${ }^{1}$, Rein \\ Estefanus Senewe ${ }^{2}$ \\ ${ }^{1}$ Universitas Pattimura, Ambon, Indonesia \\ ${ }^{2}$ Balai Pengkajian Teknologi Pertanian Maluku, Badan Litbang Pertanian, Kementerian Pertanian, Indonesia
}

*E-mail:serjana0112@gmail.com

\begin{abstract}
The Maluku Islands are renowned as the world's clove origin. Maluku is home to one of the indigenous clove germplasms known as Forest cloves. Forest Cloves are wild-type cloves found on Ambon Island, Maluku. The study's objective was to conduct an analysis of the supply chain for forest clove commodities. The investigation was conducted in the villages of Hitulama, Hitumesing, and Pulau Seram in Maluku Province, as well as in the villages of Latu and Hualoi. Primary data were collected from a sample of 25 forest clove farmers. The data analysis reveals that several parties are involved in the supply chain of Maluku's forest clove commodities, including farmers/suppliers, village-level middlemen, large collectors in the Regency City and provincial capital, Ambon City, as well as large companies in Surabaya that use forest cloves as raw material. Efforts to conserve forest cloves must be made in order to expand local potential and farmers' revenue. As a result, the wealth of Forest clove germplasm in Maluku province can be increased.
\end{abstract}

Keywords: Ambon; wild cloves; clove germplasm

\begin{abstract}
Abstrak. Kepulauan Maluku dikenal sebagai pusat asal cengkih di dunia. Maluku memiliki salah satu plasma nutfah cengkih lokal yang oleh masyarakat setempat disebut sebagai cengkih Hutan. Cengkih Hutan tergolong cengkih tipe liar yang ditemukan di beberapa wilayah di Pulau Ambon, Maluku. Tujuan penelitian adalah untuk menganalisis rantai pasok komoditas cengkih Hutan. Penelitian dilakukan di desa Hitulama, Hitumesing dan Pulau Seram di desa Latu dan Hualoi, Provinsi Maluku. Data penelitian menggunakan data primer dengan jumlah sampel sebanyak 25 petani cengkih Hutan. Hasil analisis data menunjukkan bahwa terdapat beberapa pihak yang terlibat dalam rantai pasok komoditas cengkih Hutan di Maluku yaitu petani/pemasok, tengkulak di tingkat desa, pedagang pengumpul besar yang berada di Kota Kabupaten maupun yang berada di ibukota provinsi yaitu Kota Ambon, serta perusahaan besar di Surabaya yang menggunakan cengkih Hutan sebagai bahan baku. Upaya pelestarian cengkih Hutan perlu dilakukan dalam upaya meningkatkan potensi local dan peningkatan pendapatan petani. Dengan demikian dapat meningkatkan kekayaan plasma nutfah cengkih Hutan di provinsi Maluku.
\end{abstract}

Kata Kunci: Ambon, cengkih liar, plasma nutfah cengkih

\section{PENDAHULUAN}

Kepulauan Maluku merupakan "The center of origin" sebaran cengkih di dunia (Alfian et al. 2019; Hariyadi et al. 2020b, 2020a; Mahulette et al. 2019c; Milind and Deepa 2011). Sebagai daerah asli sebaran cengkih, Provinsi Maluku memiliki kekayaan plasma nutfah cengkih yang cukup tinggi. Salah satu spesies cengkih tipe liar yang mulai banyak diminati oleh petani terutama di wilayah sebarannya di Maluku adalah cengkih Hutan. Cengkih Hutan sebarannya luas di beberapa lokasi tertentu di Pulau Ambon (Desa Hitulama, Hitumesing) dan di Pulau Seram (Desa Latu dan Hualoi) (Mahulette et al., 2019a, 2019c)(Hariyadi et al. 2020a, 2019; Mahulette et al. 2019c, 2019b, 2020a, 2020b, 2019a). 
Keberadaan cengkih Hutan sebagai plasma nutfah cengkih endemik Maluku sebelumnya kurang diminati oleh petani di wilayah sebarannya karena memiliki harga jual yang lebih rendah dibandingkan dengan cengkih lokal Maluku lainnya seperti cengkih Tuni. Rendahnya harga jual disebabkan karena cengkih Hutan tergolong cengkih tipe liar dari golongan non aromatik yang dicirikan dengan kadar eugenol yang rendah. Seiring dengan membaiknya harga jual cengkih di Indonesia sejak tahun 2005 ditambah dengan keunggulan yang dimiliki oleh cengkih Hutan menyebabkan minat petani untuk membudidayakan cengkih Hutan mulai meningkat. Cengkih Hutan memiliki kelebihan di antaranya dapat berproduksi setiap tahun, produksinya tinggi (umur $>15$ tahun dapat menghasilkan produksi bunga kering $\pm 32 \mathrm{~kg} /$ pohon), produksinya kurang berfluktuasi, dan lebih tahan terhadap organisme penggangu tanaman (OPT). Selain itu waktu berproduksi cengkih Hutan jauh lebih cepat yaitu umur 3 tahun sudah mulai berproduksi bila dibandingkan dengan cengkih lokal Tuni yang mulai berproduksi sekitar 6-8 tahun (Hariyadi et al. 2020b, 2020a). Adanya keunggulan yang dimiliki menyebabkan minat petani membudidayakan cengkih Hutan sudah mulai meluas terutama pada di wilayah di sekitar sebaran cengkih Hutan di Pulau Ambon dan Pulau Seram, Maluku.

Adanya keunggulan yang dimiliki cengkih Hutan maka perlu didukung oleh kajian keberlanjutan pasokan produksi untuk menjaga kontuinitas produksi cengkih yang dihasilkan (Fauzy et al. 2020; Kembauw et al. 2015a, 2019, 2015b; Lionardo et al. 2021; Soegijono and Kembauw 2021; Umanailo et al. 2018). Untuk itu perlu ada kerjasama berbagai pihak yang terkait dalam menjaga kontuinitas produksi. Indrajit dan Djokopranoto (2002) mengemukakan bahwa alur informasi yang antar jaringan mata rantai pasok merupakan salah satu kunci keberhasilan dalam mengoptimalkan rantai pasok sehingga dapat memberikan jaminan kepuasan bagi konsumen.

Cengkih tipe liar ini kurang diminati petani karena kurang beraroma pedas dan memiliki harga jual yang lebih rendah dibandingkan cengkih lokal lainnya seperti cengkih Tuni. Meningkatnya harga cengkih di pasar global serta keunggulan yang dimiliki cengkih Hutan menyebabkan semakin meningkatnya minat petani untuk membudidayakan cengkih Hutan di Maluku. Meningkatnya permintaan cengkih di pasar global memerlukan penelitian untuk menjaga keberlanjutan pasokan cengkih Hutan. Keberlanjutan ini diperlukan untuk menjaga kelangsungan produksi cengkih Hutan. Oleh karena itu penelitian ini bertujuan untuk menganalisis rantai pasok komoditas cengkih hutan agar supaya keberlanjutan komoditas ini dapat diandalkan dan dapat menjadi komoditas unggulan di Provinsi Maluku.

\section{METODE}

\subsection{Lokasi dan Waktu Penelitian}

Penelitian rantai pasok cengkih Hutan dilaksanakan di lokasi sebaran cengkih Hutan di Maluku yaitu di desa Hitulama dan Hitumesing di Pulau Ambon dan Desa Latu dan Hualooi di Pulau Seram. Lokasi dipilih secara purposive berdasarkan pertimbangan kedua wilayah tersebut merupakan pusat penyebaran cengkih Hutan di Maluku.

\subsection{Jenis dan Sumber Data}

Jenis data yang digunakan dalam penelitian ini adalah data primer dan data sekunder. Data primer diperoleh melalui pengamatan langsung, pencatatan, dan wawancara langsung dengan pelaku usaha cengkih Hutan yang berjumlah 25 orang untuk mengetahui menajemen rantai pasok cengkih Hutan. Data sekunder antara lain data produksi cengkih, harga produk, biaya-biaya yang dikeluarkan selama proses berlangsung, jumlah produksi yang diperoleh selama periode siklus produksi berlangsung serta data-data lainnya yang mendukung. Selain itu, data sekunder diperoleh dari Badan Pusat Statistik (BPS), Departemen Pertanian, dan literatur yang relevan.

\subsection{Metode Penentuan Responden}

Metode pengumpulan data dilakukan dengan cara observasi, wawancara, dan diskusi serta pengisian kuisioner kepada responden yaitu 25 petani cengkih Hutan di masing-masing wilayah sebarannya. Proses pengambilan sampel responden dilakukan dengan metode purposive sampling yaitu dengan pertimbangan bahwa responden yang dijadikan sampel tersebut dianggap memiliki informasi yang dibutuhkan oleh peneliti.

\subsection{Analisis Data}

Analisis data yang dilakukan pada penelitian ini terdiri dari analisis deskriptif kualitatif dan analisis kuantitatif. Analisis kualitatif dilakukan melalui pendekatan deskriptif. Analisis kualitatif dilakukan 
untuk mengetahui gambaran umum unit usaha, proses produksi, dan pengelolaan yang diterapkan. Sedangkan analisis kuantitatif dilakukan untuk menganalisis produksi pada kegiatan usaha.

\section{HASIL DAN PEMBAHASAN}

\subsection{Gambaran Umum Cengkih Hutan}

Cengkih Hutan di wilayah sebarannya di Maluku belum dapat dikatakan sebagai tanaman perkebunan utama karena hampir keseluruhan komoditas ini merupakan hasil perkembangbiakan secara alami yang tumbuh di hutan ulayat dan merupakan warisan leluhur.

Rantai pasok cengkih hutan melibatkan tiga pelaku utama:

1. Petani yang melakukan budidaya cengkih Hutan

2. Pedagang pengumpul di tingkat desa yang terlibat dalam pengumpulan dan pembelian cengkih di kebun petani

3. Pedagang pengumpul skala besar di kota kabupaten atau di pusat kota Ambon yang terlibat dalam pembelian cengkih petani

Jumlah petani cengkih di Wilayah sebaran cengkih Hutan di Kabupaten Maluku Tengah mencapai 33035 KK dan di Kabupaten Seram Bagian Barat mencapai 13.819 KK (Ditjenbun 2020). Hampir semua petani cengkih hutan di wilayah sebarannya merupakan masyarakat asli Maluku. Tanaman cengkih Hutan bersifat tahunan sehingga petani cengkih Hutan hanya mendapatkan keuntungan pada musim panen cengkih Hutan di bulan Maret. Untuk memperoleh tambahan pendapatan, petani cengkih Hutan di wilayah sebarannya dalam setahun juga memperoleh hasil dari penjualan varietas cengkih lain yang memiliki musim yang berbeda dengan cengkih Hutan yaitu cengkih varietas Tuni pada bulan September dan cengkih Raja pada bulan Juni. Harga penjulan cengkih Hutan di tingkat pengumpul besar pada musim panen tahun 2019 berkisar Rp. 65 000/kg. Produksi bunga kering cengkih Hutan milik petani yang telah berumur $>15$ tahun dapat mencapai \pm 32 $\mathrm{kg} /$ pohon sehingga dari satu pohon cengkih hutan petani bisa menghasilkan keuntungan sebesar Rp. 2 080 000/pohon.

Pedagang pengumpul di tingkat desa terlibat dalam penjualan cengkih petani ke pedagang pengumpul besar di kota kabupaten maupun di Kota Ambon. Jumlah pedagang pengumpul di desa belum diketahui secara pasti. Sebagian besar pedagang pengumpul di desa adalah pendatang dan sebagiannya adalah masyarakat lokal yang mencari tambahan pendapatan sebagai pedagang pengumpul. Pedagang pengumpul di desa biasanya membeli cengkih milik petani dalam keadaan mentah (baru selesai dipanen) ataupun sudah dalam bentuk cengkih kering. Sebagian mereka juga membeli cengkih yang masih berada di pohon dan kemudian menyewa tenaga kerja untuk memanen hasilnya. Harga bunga basah yang dibeli oleh pedagang pengumpul di tingkat desa dari petani pada musim panen tahun 2019 adalah Rp. 15 000/kg, harga bunga keringnya Rp.62 000/kg, sedangkan harga pembelian hasil cengkih yang masih berada di pohon sekitar Rp. 700 000/pohon dan tergantung dari kondisi tanaman. Penjualan hasil cengkih ke pedagang pengumpul di desa biasanya terjadi pada petani yang memiliki kebun cengkih yang yang luas dan lokasinya jauh dari tempat penjualan. Hasil pembelian cengkih oleh pedagang pengumpul di desa biasanya dijual ke padagang pengumpul besar di kota kabupaten ataupun ke padagang pengumpul besar di kota Ambon.

Pedagang pengumpul besar di tingkat kabupaten maupun di kota Ambon sebagian besar adalah warga Indonesia keturunan Tianghoa yang sudah lama menetap di Maluku. Pedagang pengumpul ini selanjutnya melakukan pembelian cengkih petani dan mengirimkan ke perusahaan manufaktur di Surabaya. Harga pembelian bunga cengkih Hutan kering oleh pedagang pengumpul besar pada tahun 2019 adalah sebesar Rp. 65 000/kg.

\subsection{Produk dan Pasar}

Produk utama cengkih Hutan sejauh ini adalah bunga (flower bud). Rata-rata dimanfaatkan sebagai bahan pencampur rokok untuk industri pabrik rokok kretek. Pengolahan bahan baku cengkih Hutan menjadi produk turunan yang lain seperti minyak atsiri (essential oil) belum dilakukan karena dianggap memiliki kadar minyak dan kadar eugenol yang rendah. Kadar minyak atsiri pada bagian bunga cengkih Hutan adalah sekitar $\pm 20 \%$, tangkai bunga $\pm 20 \%$ dan daun $\pm 21 \%$ (Mahulette et al. 2019b, 2020a, 2019c). Rendahnya kadar minyak dan kadar eugenol menyebabkan produk utama yang dihasilkan sejauh ini hanya sebatas bunga cengkih kering (dry flower bud). Produksi bunga cengkih Hutan yang dibeli dari petani biasanya langsung dijual setelah dikeringkan tanpa melewati proses diversifikasi untuk menjadi produk turunan yang lain. Bunga cengkih Hutan biasanya dibeli oleh 
pedagang pengumpul besar kemudian dikirimkan ke perusahaan besar di Surabaya melalui pelabuhan laut Yos Sudarso Ambon.

\subsection{Rantai Pasok Komoditas Cengkih Hutan di Maluku \\ 3.3.1. Pengelolaan Cengkih Hutan oleh Petani/Pemasok}

Musim panen cengkih Hutan di wilayah sebarannya di Maluku berlangsung pada bulan Maret. Pemanenan cengkih Hutan umumnya berlangsung di wilayah sebarannya di Maluku yaitu di Pulau Ambon: desa Hitulama dan Hitumesing Kab.Maluku Tengah. dan Pulau Seram: desa Latu dan Hualoi) Kab. Seram Bagian Barat. Bagian yang dipanen adalah bunga cengkih (flower bud) yang telah berumur 3 bulan sejak antesis. Proses pemanenan hingga bunga cengkih siap dijual melewati beberapa tahapan kegiatan, yaitu: pemetikan, proses penjemuran, proses pembersihan, dan penyimpanan. Adapun alur pemindahan bunga cengkih hasil panen ke pedagang pengumpul di tingkat desa atau ke pedagang pengumpul besar di kota kabupaten SBB atau di kota Ambon disajikan pada Gambar 1.

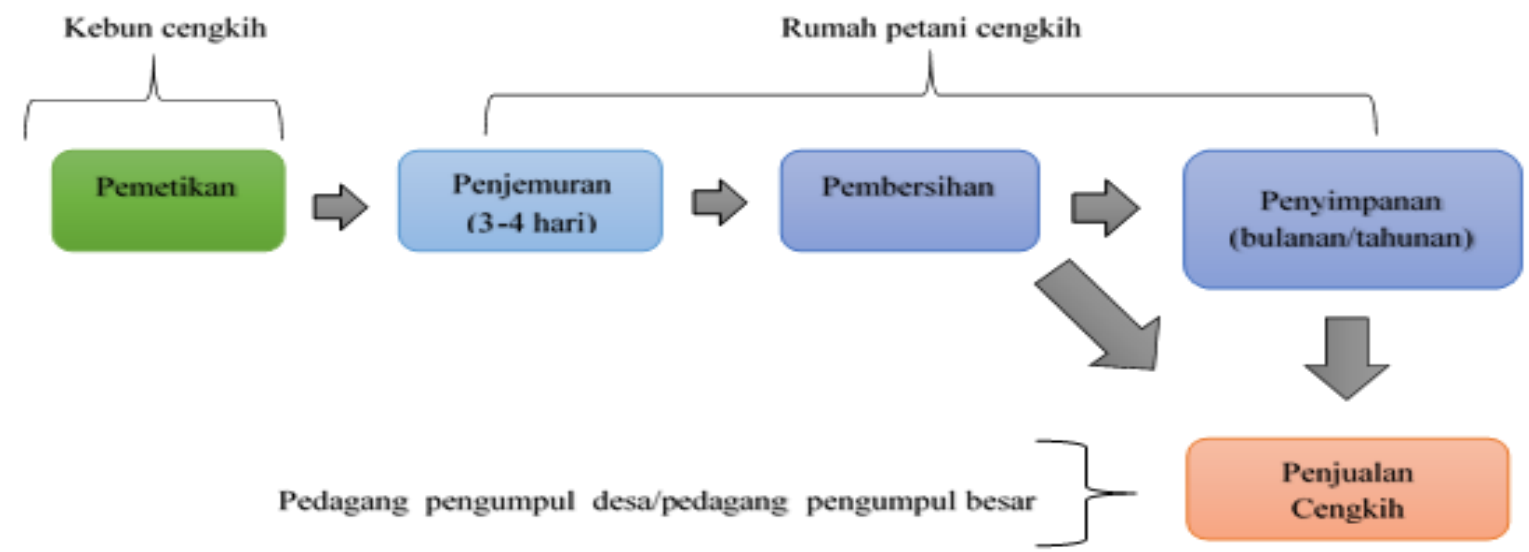

Gambar 1. Alur Proses Pemindahan Cengkih Hutan dari Kebun Petani ke Pedagang Pengumpul Desa/Pedagang Pengumpul Besar

\subsubsection{Pedagang pengumpul di tingkat desa}

Tidak semua hasil panen cengkih Hutan petani langsung dijual ke pedagang pengumpul besar di kota kabupaten ataupun di kota Ambon, akan tetapi sebagian dari hasil panen petani dijual ke pedagang pengumpul di desa yang mendatangi kebun petani. Penjualan ke pedagang pengumpul di desa biasanya dilakukan terutama pada lokasi kebun cengkih petani yang jauh dari akses jalan. Adanya himpitan ekonomi juga menjadi alasan petani untuk menjual hasil cengkihnya ke pedagang pengumpul di desa. Sebagian pedagang pengumpul di desa tidak hanya membeli hasil panen cengkih petani yang telah dirontokkan, akan tetapi sebagian dari mereka juga membeli bunga cengkih yang masih berada di pohon, kemudian menyewa tenaga kerja untuk membantu melakukan pemanenan. Harga penjualan bunga cengkih Hutan yang masih berada di pohon pada tahun 2019 bekisar Rp. 700 000/pohon, sedangkan harga pembelian bunga cengkih mentah yang telah dirontokkan oleh petani/pemasok berkisar Rp. 15 000/kg dan harga bunga cengkih kering Rp. 62 000/kg.

\subsubsection{Pedagang pengumpul besar di kota kabupaten dan kota Ambon}

Cengkih Hutan yang telah siap dijual dibawa ke padagang pengumpul besar di kota kabupaten ataupun dibawa langsung ke Kota Ambon untuk dijual. Pedagang pengumpul cengkih Hutan sama seperti pedagang pengumpul cengkih varietas lainnya. Hasil panen cengkih Hutan di wilayah sebarannya di Kabupaten Maluku Tengah (Pulau Ambon) biasanya langsung dijual ke pedagang pengumpul besar yang berlokasi di pusat kota Ambon, sedangkan pada wilayah Seram Bagian Barat biasanya dijual ke pedagang pengumpul yang ada di kota Kabupaten SBB ataupun dibawa langsung ke pedagang pengumpul yang ada di kota Ambon

Cengkih yang masuk ke pedagang pengumpul besar di kota kabupaten ataupun di Kota Ambon melewati proses di antaranya: pemeriksaan kebersihan, penimbangan, pengemasan dan penyimpanan. Cengkih tersebut kemudian selanjutnya disimpan dalam waktu yang tidak menentu ( $\pm 1-2$ bulan) untuk dikirim ke perusahaan besar atau perusahaan manufaktur di Surabaya melalui pelabuhan laut Yos 
Sudarso Ambon. Harga penjulan cengkih Hutan di tingkat pedagang pengumpul besar pada musim panen bulan Maret 2019 berkisar Rp. 65 000/kg

\subsection{Alur Rantai Pasok Komoditas Cengkih Hutan di Maluku}

Pihak yang terlibat dalam aktivitas rantai pasok komoditas cengkih Hutan di Maluku terdiri atas:

1. Petani cengkih Hutan sebagai pemasok.

2. Tenaga pemetik dan perontok cengkih Hutan di kebun petani.

3. Pedagang pengumpul di tingkat desa yang membeli hasil cengkih Hutan petani/pemasok.

4. Penyedia jasa angkutan untuk mengangkut hasil cengkih ke pedagang pengumpul besar.

5. Pedagang pengumpul besar di kota kabupaten atau di pusat kota Ambon yang membeli hasil cengkih Hutan petani/pemasok.

6. Tenaga kerja di lokasi pedagang pengumpul besar di kota kabupaten atau di pusat kota Ambon.

7. Penyedia jasa kontainer untuk pengiriman cengkih ke Surabaya.

8. Pemborong di pelabuhan Yos Sudarso Ambon yang akan mengirimkan cengkih ke Surabaya.

9. Perusahaan yang menggunakan cengkih Hutan sebagai bahan baku produk (manufacture).

\subsection{Rantai Pemasaran}

Hasil identifikasi terhadap petani cengkih Hutan di Maluku, sebagian besar menyatakan tidak memiliki kendala dalam memasarkan hasil panen cengkih mereka. Hasil panen petani biasanya dibeli langsung di kebun oleh pedagang pengumpul di desa ataupun dijual langsung ke pedagang pengumpul besar di kota kabupaten ataupun di Kota Ambon. Hal yang paling dirasakan petani dalam sistem pemasaran cengkih Hutan adalah harga jual sepenuhnya ditentukan oleh pedagang pengumpul. Petani memiliki posisi yang sangat lemah dalam mata rantai pemasaran cengkih Hutan (Elim et al. 2019; Mardiana and Kembauw 2021; Paley et al. 2021; Putra et al. 2020; Sinay and Kembauw 2021). Pembentukan harga sepenuhnya berada pada pedagang pengumpul di desa dan pedagang pengumpul besar di kota kabupaten maupun di kota Ambon.

Sistem rantai pemasaran komoditas cengkih Hutan di Maluku terdapat 2 rantai. Rantai pertama adalah dari petani ke pedagang pengumpul di desa lalu ke pedagang pengumpul besar di kota kabupaten atau Kota Ambon. Rantai pemasaran yang kedua adalah dari petani ke pedagang pengumpul besar di kota kabupaten atau di kota Ambon. Dari pedagang pengumpul besar pada kedua mata rantai tersebut kemudian cengkih Hutan dijual ke perusahaan (manufacture) yang menggunakan cengkih sebagai bahan baku yang berlokasi di Surabaya. Kedua mata rantai tersebut disajikan pada Gambar 2.
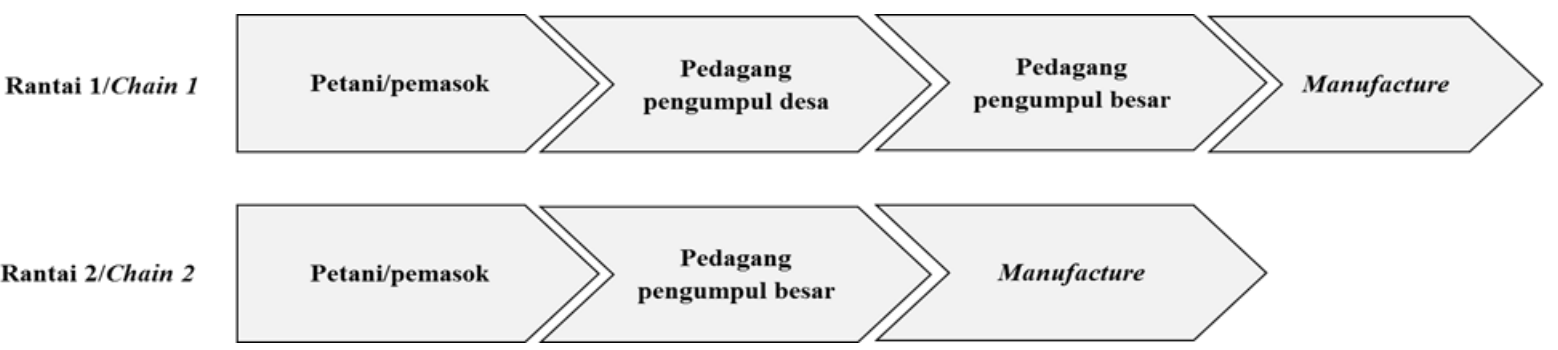

Gambar 2. Rantai Pemasaran Cengkih Hutan di Maluku

\section{KESIMPULAN}

Penelitian ini mendiskripsikan rantai pasok cengkih Hutan di beberapa desa di Maluku. Data penelitian menggunakan data primer, dukumpulkan melalui wawancara kepada 25 petani sampel. Hasil penelitian menunjukkan bahwa terdapat beberapa pihak yang terlibat dalam rantai pasok komoditas cengkih Hutan di Maluku yaitu petani/pemasok, tengkulak di tingkat desa, pedagang pengumpul besar yang berada di Kota Kabupaten dan di Kota Ambon, serta perusahaan besar di Surabaya. Sistem rantai pemasaran komoditas cengkih Hutan di Maluku terdiri atas 2 rantai pemasaran yaitu dari petani ke pedagang pengumpul di desa lalu ke pedagang pengumpul besar di kota kabupaten atau Kota Ambon dan kedua adalah dari petani langsung ke pedagang pengumpul besar di kota kabupaten dan di kota Ambon kemudian ke perusahaan besar yang menggunakan cengkih Hutan sebagai bahan baku yang berlokasi di Surabaya. Mengingat cengkih Hutan sudah digunakan sebagai 
bahan baku salah satu perusahaan di Surabaya, maka perlu dilakukan upaya pelestarian cengkih Hutan sehingga dapat meningkatkan petani cengkih Hutan dan dapat meningkatkan potensi kearifan local provinsi Maluku.

\section{DAFTAR PUSTAKA}

Alfian A, Mahulette AS, Zainal M, Hardin, Bahrun AH. 2019. Morphological character of raja clove (Syzygium aromaticum L. Merr \& Perry .) native from Ambon Island. In The First International Conference of Interdisiplinary Research on Green Environment Approach for Sustainable Development (ICROEST 2019), Makassar: IOP Conference Series: Earth and Environmental Science, pp. 1-4.

Ditjenbun. 2020. Statistik Perkebunan Indonesia 2018-2020 (Cengkih). Jakarta (ID): Kementerian Pertanian. $70 \mathrm{hlm}$.

Elim HI, Kembauw E, Siahainenia RH, Lamerkabel JSA, Sahusilawane AM, Djoko SW, Setha B. 2019. Heavenly small islands simple technology \& its cultural economy impacts in Maluku, Indonesia: a new proposed Multitasking Philosophy in Diversity (MPD). Science Nature 2(4):192-207.

Fauzy P, Pattiasina M, Kembauw E. 2020. Analisis pendapatan agroindustri produk olahan kelapa sentra bisnis Yanmel Desa Yainuelo, Kecamatan Amahai, Kabupaten Maluku Tengah. AGRILAN : Jurnal Agribisnis Kepulauan Pendahuluan 8(3):261-274.

Hariyadi, Mahulette AS, Yahya S, Wachjar A. 2020a. Morphological characters and essential oil constituents extracted of two clove varieties (Syzygium aromaticum (L.) Merr. \& L. M. Perry.) from Ambon Island, Indonesia. Plant Archives 20(1):2208-2214.

Hariyadi, Mahulette AS, Yahya S, Wachjar A. 2020b. Agro-morphologies and physicochemical properties of flower bud, stem and leaf oils in two clove varieties (Syzygium aromaticum L . Merr . and Perry .) originated from Ambon island. Chiang Mai University Journal of Natural Sciences 19(3):516-530.

Hariyadi, Mahulette AS, Yahya S, Wachjar A. 2019. Measuring the potential of biomass, carbon storage, and carbon sink of forest cloves. In The 1st International Seminar on Natural Resources and Environmental Management (ISenREM 2019), Bogor: IOP Conf. Series: Earth and Environmental Science 399 (2019) 012063, pp. 1-9.

Indrajit E. R. Dan Richardus, D. 2002. Konsep Manajemen Supply Chain: Cara Baru Memandang Mata Rantai Penyediaan Barang. Jakarta: PT. Grasindo.

Kembauw E, Sahusilawane AM, Sinay LJ. 2015a. Sektor pertanian merupakan sektor unggulan terhadap pembangunan ekonomi Provinsi Maluku. Agriekonomika 4(2):210-220.

Kembauw E, Soekiman JFXS, Lydia EL, Shankar K, Huda M. 2019. Benefits of corporate mentoring for business organization. Journal of Critical Reviews 6(5):101-106.

Kembauw E, Anindita R, Mustadjab MM, Muhaimin AW. 2015b. Agricultural sector investment impact of economy Province Maluku. Journal of Economics and Sustainable Development 6(6):31-37.

Lionardo A, Bugis M, Umanailo MCB, Kembauw E, Kurniawan R. 2021. Labor social capital and human resource management for eucalyptus oil supply chain. Psychology and Education 58(4):1951-1958.

Mahulette AS, Hariyadi, Yahya S, Wachjar A, Alfian A. 2019a. Morphological traits of Maluku native forest clove (Syzygium aromaticum L. Merr \& Perry.). Journal of Tropical Crop Science 6(2):105-111.

Mahulette AS, Yahya S, Wachjar A. 2019b. The physicochemical components and characteristic from essential oils of forest cloves Syzygium aromaticum (Myrtaceae) in Maluku Province, Indonesia. Plant Archives 19(2):466-472.

Mahulette AS, Hariyadi, Yahya S, Wachjar A, Marzuki I. 2019c. Morpho-agronomical diversity of forest clove in Moluccas, Indonesia. Hayati Journal of Biosciences 26(4):156-162. doi:10.4308/hjb.26.4.156.

Mahulette AS, Hariyadi, Yahya S, Wachjar A. 2020a. Physico-chemical properties of clove oil from three forest clove accession groups in Maluku. In 1st International Conference on Sustainable Plantation (1st ICSP 2019), Bogor: IOP Conf. Series: Earth and Environmental Science 418 (2020) 012028 IOP, pp. 1-8. 
Mahulette AS, Alfian A, Zainal M, Nendissa JI, Wattimena AY, Tanasale VL, Makaruku MH, Laisina JKJ. 2020b. Growth of forest clove seedlings at different concentrations of paclobutrazol. In The 2nd International Conference of Interdisciplinary Research on Green Environmental Approach for Sustainable Development, Makassar: IOP Conf. Series: Earth and Environmental Science 575 (2020) 012081, pp. 1-7.

Mardiana H, Kembauw E. 2021. The Role of Diffusion of Innovation in Agricultural to Compete in Asean Community The Role of Diffusion of Innovation in Agricultural to Compete in Asean Community. In IOP Conf. Series: Earth and Environmental Science 755 (2021) 012074, pp. 113.

Milind P, Deepa K. 2011. Clove: A champion spice. International Journal of Research in Ayurveda \& Pharmacy 2(1):47-54.

Paley WB, Kembauw E, Tuhumury MTF. 2021. Strategi pengembangan agroindustri kelapa ud wootay coconut di Kecamatan Teon Nila Serua Kabupaten Maluku Tengah. AGRILAN : Jurnal Agribisnis Kepulauan Pendahuluan 9(1):21-31.

Putra P, Kembauw E, Sebayang A, Mukhlis H, Fauzi. 2020. State owned enterprise for the creation of prosperity for all Indonesian. Journal of Critical Reviews 7(08):2032-2036.

Sinay LJ, Kembauw E. 2021. Monthly rainfall components in Ambon City: evidence from the serious time analysis. In IOP Conf. Series: Earth and Environmental Science 755 (2021) 012079, pp. 18.

Soegijono SP, Kembauw E. 2021. Sustainable development of papalele's household from environmental issue. In IOP Conf. Series: Earth and Environmental Science 755 (2021) 012026, pp. $1-6$.

Umanailo MCB, Kembauw E, Mujib F, FaisAssagaf SS, Umanailo R, Meifilina A, Hentihu I, Kasmawati K, Hamiru H, Yusuf N. 2018. Moral economics and survival strategies of the upland rice farmers. International Journal of Innovative Science and Research Technology 3(7):616622. 